\title{
Identifying a rainfall event threshold triggering herbicide leaching by preferential flow
}

\author{
G. S. McGrath, ${ }^{1}$ C. Hinz, ${ }^{1}$ M. Sivapalan, ${ }^{2,3,4}$ J. Dressel, ${ }^{5,6}$ T. Pütz, ${ }^{5}$ and H. Vereecken ${ }^{5}$
}

Received 5 October 2008; revised 1 September 2009; accepted 11 September 2009; published 16 February 2010.

[1] How can leaching risk be assessed if the chemical flux and/or the toxicity is highly uncertain? For many strongly sorbing pesticides it is known that their transport through the unsaturated zone occurs intermittently through preferential flow, triggered by significant rainfall events. In these circumstances the timing and frequency of these rainfall events may allow quantification of leaching risk to overcome the limitations of flux prediction. In this paper we analyze the leaching behavior of bromide and two herbicides, methabenzthiazuron and ethidimuron, using data from twelve uncropped lysimeters, with high-resolution climate data, in order to identify the rainfall controls on rapid solute leaching. A regression tree analysis suggested that a coarse-scale fortnightly to monthly water balance was a good predictor of short-term increases in drainage and bromide transport. Significant short-term herbicide leaching, however, was better predicted by the occurrence of a single storm with a depth greater than a $19 \mathrm{~mm}$ threshold. Sampling periods where rain events exceeded this threshold accounted for between $38 \%$ and $56 \%$ of the total mass of herbicides leached during the experiment. The same threshold only accounted for between $1 \%$ and $10 \%$ of the total mass of bromide leached. On the basis of these results, we conclude that in this system, the leaching risks of strongly sorbing chemicals can be quantified by the timing and frequency of these large rainfall events. Empirical and modeling approaches are suggested to apply this frequentist approach to leaching risk assessment to other soil-climate systems.

Citation: McGrath, G. S., C. Hinz, M. Sivapalan, J. Dressel, T. Pütz, and H. Vereecken (2010), Identifying a rainfall event threshold triggering herbicide leaching by preferential flow, Water Resour. Res., 46, W02513, doi:10.1029/2008WR007506.

\section{Introduction}

[2] If asked to characterize the risk of pesticide movement to groundwater, there are two aspects one should consider. The first is the consequences of the application. Most modeling and field studies consider this aspect, as they focus on the prediction or measurement of the concentration which reaches a certain depth. However, low concentrations of a chemical can potentially pose a risk [Hayes et al., 2003], the toxicity is often uncertain [McCarty and Borgert, 2006], and model predictions of the concentration are often highly uncertain [Giambelluca et al., 1996]. Therefore, there appears to be a need for alternatives to flux prediction for risk assessment.

[3] Some modeling studies consider the second component of a risk matrix (Table 1), the likelihood. However, those

\footnotetext{
${ }^{1}$ School of Earth and Environment, University of Western Australia, Crawley, Western Australia, Australia.

${ }^{2}$ Centre for Water Research, University of Western Australia, Crawley, Western Australia, Australia.

${ }^{3}$ Department of Water Management, Faculty of Civil Engineering and Geosciences, Delft University of Technology, Delft, Netherlands.

${ }^{4}$ Department of Geography and Department of Civil and Environmental Engineering, University of Illinois at Urbana-Champaign, Urbana, Illinois, USA.

${ }^{5}$ Agrosphere, ICG-4, Forschungszentrum Jülich GmbH, Jülich, Germany.

${ }^{6}$ Now at BASF SE, Limburgerhof, Germany.
}

Copyright 2010 by the American Geophysical Union. 0043-1397/10/2008WR007506\$09.00 modeling studies focus on deriving probability distributions of leached amounts, and therefore suffer the same limitations just described. No studies have yet considered the frequency of leaching events as a possible measure of leaching risk. This is relevant for many pesticides and metals which strongly sorb to the soil as there is a significant body of evidence which indicates that they are transported predominantly through fast flow pathways, such as surface runoff and preferential flow episodically, during discrete rainfall events [Leonard, 1990; Flury, 1996; Kladivko et al., 2001]. Therefore, knowledge of the frequency of these events and their timing with respect to chemical application may provide a hitherto neglected opportunity to quantify leaching risk.

[4] In the unsaturated zone these rapid flow pathways often consist of biopores, structural voids and textural heterogeneities. The triggering of flow through these macropores occurs when the rainfall intensity exceeds the infiltration capacity of the surrounding soil matrix or when the soil wets sufficiently to fill the largest pores [Beven and Germann, 1982]. These thresholds are why pesticide leaching appears episodic, as not every rainfall event will trigger rapid preferential flow. Another important consideration is that the water in preferential flow pathways needs to have interacted significantly with the soil matrix where the pesticides reside. For those pesticides which strongly sorb to soil this is often near the soil surface [Flury, 1996; Allaire et al., 2002]. Rapid pesticide transport associated with macropore flow is therefore driven by the upper boundary 
Table 1. Typical Risk Matrix

\begin{tabular}{ccccc}
\hline & & \multicolumn{3}{c}{ Consequences } \\
\cline { 3 - 5 } Frequency $\left(\mathrm{d}^{-1}\right)$ & Likelihood & Insignificant & Minor & Major \\
\hline 1 & certain & moderate & high & extreme \\
$10^{-1}$ & likely & moderate & high & high \\
$10^{-2}$ & probable & low & moderate & high \\
$10^{-3}$ & unlikely & low & low & moderate \\
$10^{-4}$ & improbable & low & low & moderate \\
\hline
\end{tabular}

condition, in particular rainfall events which cause these thresholds to be exceeded.

[5] Recently the structure of rainfall has begun to be included within a developing theory of preferential flow and pesticide leaching [Heppell et al., 2002; Malone et al., 2004; Struthers et al., 2007; McGrath et al., 2007, 2008a, 2008b; Nolan et al., 2008]. Heppell et al. [2002] used repeated applications of a mobile tracer at the soil surface to identify a combination of rain event duration and rain event intensity as controls on the amount of preferential flow occurring in a heavy clay soil. The distribution of rainfall within an event is also known to have a significant impact upon the amount of chemical preferentially transported [Malone et al., 2004; McGrath et al., 2008a]. Nolan et al. [2008] recently conducted classification and regression tree analysis of modeled pesticide transport to evaluate the role of various climatic factors. They found that both short, i.e., large rain events shortly after application, and long time scale, i.e., seasonality in climate, controlled leached amounts. For large cumulative leaching they also found seasonal rainfall thresholds as a control in association with clay content. The role of individual events or the frequency of preferential flow events was not assessed. These studies suggest that with knowledge of the statistical properties of rainfall, which trigger preferential flow, we may be able to predict how and when different soils vary in their susceptibility to rapid pesticide transport. Experimental studies however, have so far failed to quantify the rain event controls on pesticide transport [Flury, 1996; Kladivko et al., 2001]. In this paper we seek to quantify those rain events by applying a novel analysis of a high-quality herbicide leaching experiment. The experiment entailed a 3 year lysimeter monitoring program, measuring the transport of two herbicides: methabenzthiazuron (MBT) (CAS 18691-97-9), isotope labeled ethidimuron (ETD) (CAS 30043-49-3), and a bromide tracer [Dressel, 2003]. Preferential flow has been established as a significant component of the water balance [Kasteel et al., 2006] and to rapidly transport pesticides [Pütz et al., 1998] in the soils used in this experiment.

[6] As bromide is very mobile and will be rapidly moved below the surface of the soil, we expect that in the dynamics of transport, the effect of fluctuations of rainfall at the upper boundary will be significantly dampened. Therefore, coarse resolution rainfall and average water balance statistics will describe its transport. The herbicides however strongly adsorb to the soil, and will persist near the soil surface for much longer. Previous modeling has demonstrated that in the absence of preferential flow the herbicides are not expected to be transported through the lysimeter during the experiment [Dressel, 2003]. Therefore, given the proximity of these chemicals to the upper boundary and the thresholds required to trigger rapid preferential flow near the soil surface, we hypothesize that rainfall statistics which reflect intense rain events will predict the occurrence of potentially significant herbicide leaching periods.

[7] Rainfall is characterized here by indicators such as rainfall event properties such as the interstorm period, storm duration and storm intensity as well as time averaged rainfall intensities for various intervals ranging from 10 minutes up to the temporal resolution of solute flux measurements which ranges from 2 weeks to 2 months. Using regression tree analysis these storm and rainfall resolution statistics are related to the water flow and solute transport observed in the experiment. The data-based approach was adopted in order to identify the rainfall controls, independent of any hydrological model structures. The paper is organized as follows. First we provide an overview of the experiment and relevant results from that work. After an initial exploratory data analysis the results of the regression tree analyses are discussed. On the basis of these results we propose a simple storm event indicator which can be used to give a prediction of the probability and timing of large herbicide leaching events in the experimental system. Finally, we outline how a frequentist approach to leaching risk could be implemented using these results.

\section{Methods}

[8] The data used here were generated as part of a larger study aimed at evaluating solute transport at the plot and field scales [Pütz et al., 1999; Dressel, 2003]. The following briefly summarizes the experimental design, relevant results from that work and our analysis of it.

\subsection{Site Description}

[9] The leaching experiment was conducted simultaneously at two sites: Merzenhausen, Jülich, Germany (MRZ) located at approximately $6^{\circ} 17^{\prime} 46^{\prime \prime}$ longitude $50^{\circ} 55^{\prime} 47^{\prime \prime}$ latitude; and at Institute Agrosphäre, Forschungszentrum Jülich (FZJ) located approximately $10 \mathrm{~km}$ south east of MRZ. In the 25 years prior to the experiment the mean daily air temperature at FZJ varied seasonally between -5 to $24^{\circ} \mathrm{C}$ in phase with the evaporation $\left(92 \mathrm{~mm}\right.$ month $^{-1}$ to $9 \mathrm{~mm}$ month $\left.{ }^{-1}\right)$ and rainfall $\left(78 \mathrm{~mm}\right.$ month $^{-1}$ to $51 \mathrm{~mm}$ month ${ }^{-1}$ ). The soil used in the experiments is classified as silt loam, and reportedly had earthworm burrows in abundance up to $2.5 \mathrm{~m}$ below ground surface [Pütz et al., 1998]. The saturated hydraulic conductivity of the soil at $10-16 \mathrm{~cm}$ depth was determined to be approximately $17.5 \mathrm{~mm} \mathrm{~h}^{-1}$ [Dressel, 2003]. Table S1 in the auxiliary material provides more detail on soil properties, as determined by Pütz [1993]. ${ }^{1}$

\subsection{Lysimetry}

[10] During November 1993, a total of 12 stainless steel cylinders were cored into the ground at the MRZ field site to collect undisturbed soil monoliths. These cylinders were $110 \mathrm{~cm}$ tall with an upper surface area of 0.5 or $1.0 \mathrm{~m}^{2}$. The cylinders, containing the soil, were then assembled into lysimeters. In October 1995 six of these lysimeters were

\footnotetext{
${ }^{1}$ Auxiliary materials are available in the HTML. doi:10.1029/ 2008WR007506.
} 
(a)

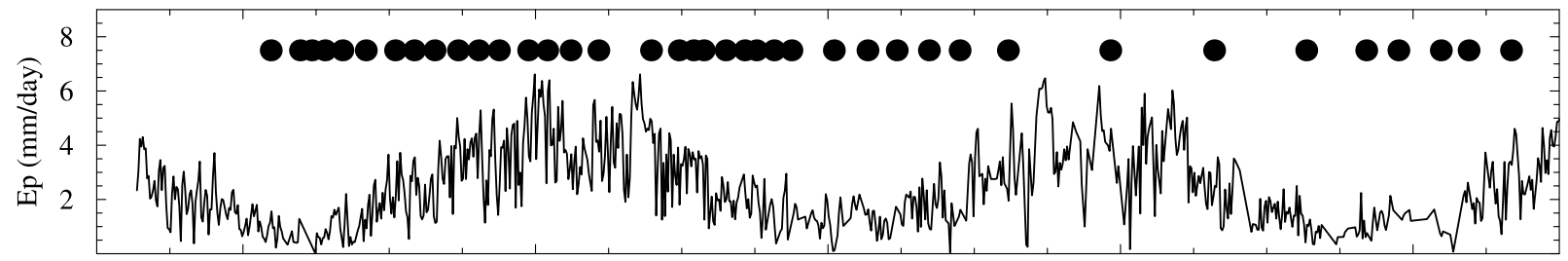

(b)

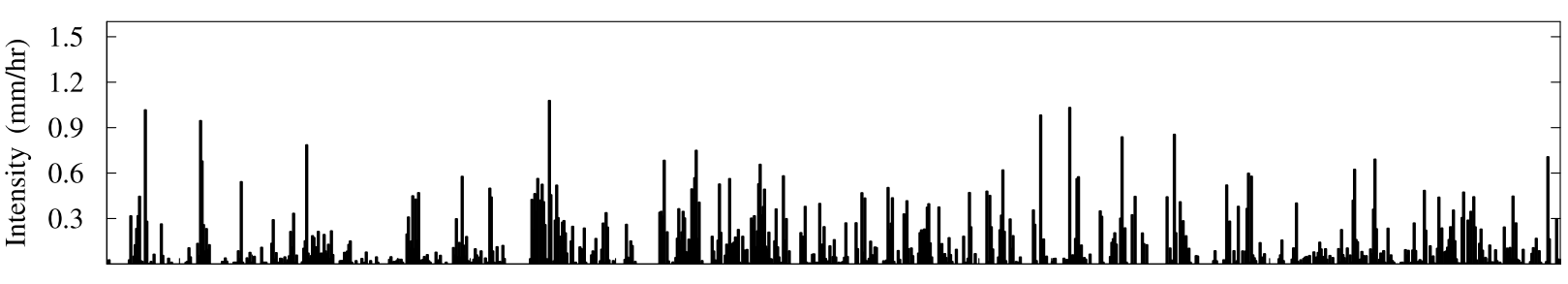

(c)
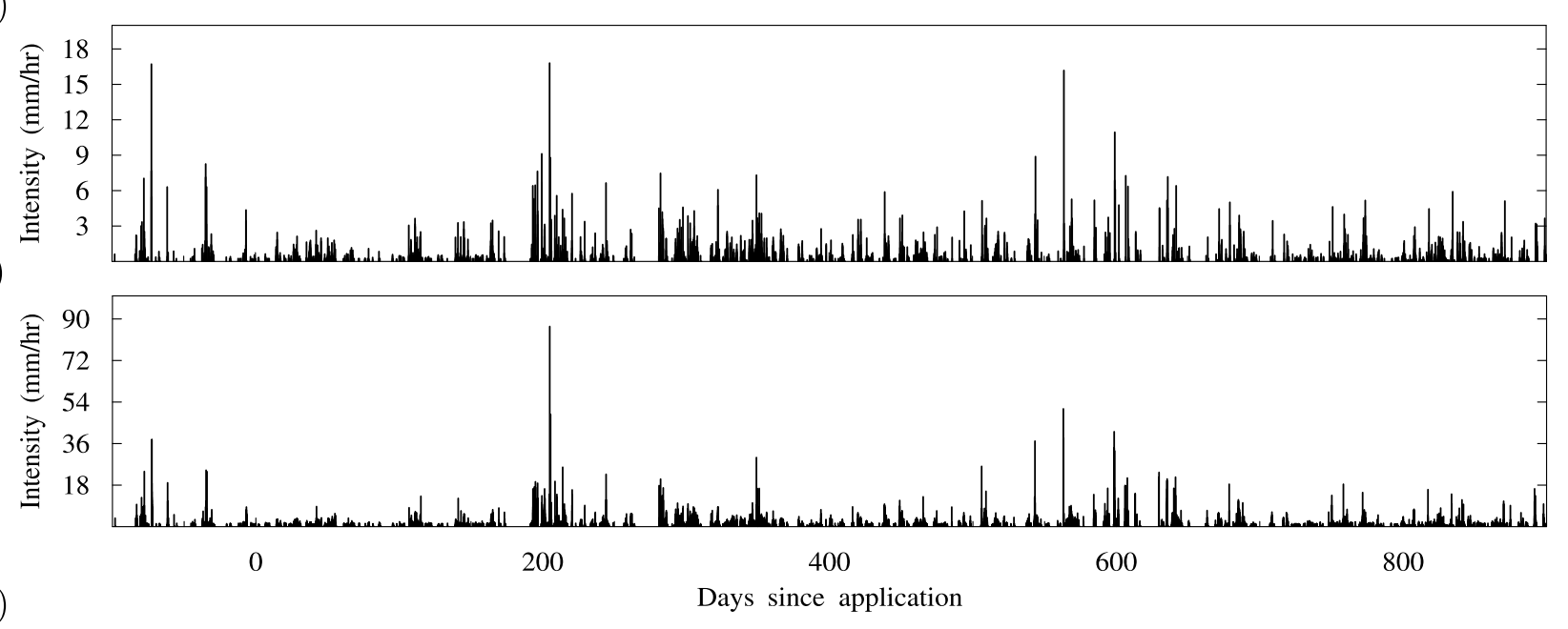

Figure 1. Evaporation and rainfall at different temporal resolutions at Forschungszentrum Jülich. Shown are (a) daily potential evaporation and leachate sampling dates (circles), (b) daily averaged rainfall intensity, (c) hourly averaged rainfall intensity, and (d) 10 min resolution rainfall intensity.

placed in situ at MRZ to be studied in conjunction with a field-scale experiment, while the remaining six were installed at the lysimeter facility at FZJ. Following spray application of all three substances on 13 November 1997, percolate was collected from each lysimeter on 43 occasions between 2 December 1997 and 15 November 2000, initially at weekly to fortnightly intervals, then increasing to monthly then bimonthly sampling. The lysimeters were maintained free of vegetation by occasional shallow mechanical weeding and application of a commercial grade, broad spectrum herbicide, Roundup ${ }^{\mathbb{B}}$, the active ingredient of which is glyphosate. These applications occurred on 2 May 1997, 2 July 1997, and 5 November 1999 at $4 \mathrm{~L} \mathrm{ha}^{-1}$. The lysimeters were otherwise not irrigated during the experiment.

\subsection{Climate Data}

[11] Weather stations collected data from September 1996 to June 2000. The weather station at MRZ was located within $50 \mathrm{~m}$ of all six lysimeters while at FZJ the weather station was approximately $200 \mathrm{~m}$ from the lysimeter facility. Rainfall was measured with a tipping bucket rain gauge (Thiess, Göttingen) at a resolution of 10 minutes. Wind speed at $0.02 \mathrm{~m}$ (heat wire anemometer, Type 8470, TSI, Aachen Germany), 0.2 and $2 \mathrm{~m}$ (bowl anemometer, Porton A100, Walz, Effeltrich, Germany), global radiation at $2 \mathrm{~m}$ (pyranometer LI-200SA, LI-COR, Lincoln, USA), air temperature and humidity at $2 \mathrm{~m}$ (psychrometer, Thiess, Göttingen, Germany) were also measured at 10 min intervals. Evaporation reported here is presented as potential evaporation, calculated using the Penman equation (see Dressel [2003, p. 101] for details). Rainfall and potential evaporation measured at FZJ, as well as leachate sampling times are shown in Figure 1.

\subsection{Chemical Application and Analysis}

[12] The chemicals used in the study consisted of bromide $\left(\mathrm{Br}^{-}\right)$as potassium bromide $(\mathrm{KBr})$ and the herbicides methabenzthiazuron (MBT), 1-Benzothiazol-2-yl-1,3dimethylurea, and ethidimuron (ETD), 1,3-Dimethyl-3(5-ethylsulfonyl-1,3,4-thiadiazol-2-yl)-urea, which was 14C-labeled in the thiadiazole- 2 position. The chemicals were applied to the lysimeters on 13 November 1997 at $1.57 \mathrm{~kg} \mathrm{ha}^{-1}, 1.72 \mathrm{~kg} \mathrm{ha}^{-1}$ of active ingredient for ETD and MBT, respectively, and $311 \mathrm{~kg} \mathrm{ha}^{-1}$ for $\mathrm{Br}^{-}$with a pesticide sprayer by hand in a $0.2 \mathrm{~mm}$ pulse. The herbicides were applied in a formulation with comparable properties to the commercial grade products Ustilan $^{(B)}$ (ETD) and Tribunil ${ }^{\mathbb{E}}$ (MBT) [Dressel, 2003].

[13] Chemical analysis of the herbicides was conducted by HPLC-MS/MS. Radioactivity was measured by liquid scintillation counting. Bromide was analyzed by ion exchange 
chromatography. The quantitation limits established for the analyses were $0.05 \mu \mathrm{g} \mathrm{L}^{-1}$ (ETD), $0.01 \mu \mathrm{g} \mathrm{L}^{-1}$ (MBT) and $0.05 \mathrm{mg} \mathrm{L}^{-1}\left(\mathrm{Br}^{-1}\right)$ [Dressel, 2003]. Cumulative water flow and solute transport measured by each lysimeter are shown in Figure 2.

[14] Laboratory batch experiments determined sorption of the herbicides to the soil followed Freundlich isotherms and degradation was found to decrease exponentially with time [Brumhard, 1991; Zetler, 1998; Wüstemeyer, 2000] (as cited by Dressel [2003]). MBT was approximately 20 times more strongly sorbing to the soil than ETD [Dressel, 2003]. Selected chemical properties are summarized in the auxiliary material (Table S2). For the Ap horizon, sorption parameters are similar to reported values in the literature for MBT, where Freundlich $K_{\text {foc }}$ was found to be $633 \mathrm{~L}^{3-1 / n}$ $\mathrm{kg}^{-1 / n}$ and the exponent $\left(n^{-1}\right) 0.69$ [Dressel, 2003; Baez et al., 2001]. For ETD the Freundlich $K_{\text {foc }}$ increased from $27 \mathrm{~L}^{3-1 / n} \mathrm{~kg}^{-1 / n}$ to $144.8 \mathrm{~L}^{3-1 / n} \mathrm{~kg}^{-1 / n}$ over several batch equilibrium sorption/desorption experiments, while $n^{-1}$ was found to be 0.86 . Measured degradation rates showed that MBT was 4.5 times more rapidly degraded than ETD, with half-lives of 44.6 and 198 days, respectively [Dressel, 2003]. MBT degradation rates were also comparable to previously published values [Rouchaud et al., 1998]. Sorption and degradation values for ETD could not be found in the literature prior to submission.

\subsection{Data Preparation: Leaching Variables}

[15] The average leachate behavior of the six lysimeters was used to generate a "field" averaged value for both sites. As described in more detail in section 3, the drainage rate was found to be nearly constant over long periods of time. Within the 3 year observation record, five distinct drainage periods ("regimes") were observed, each with a constant drainage rate that is different from the preceding or subsequent regime. During each of these regimes solute dissipation was also found to decay exponentially with time (see Figures 3b, 3c, and 3d). In order to better capture short-term variations in leaching, the effect of these regimes was removed by subtracting the regime average dissipation (drainage) rate from the dissipation (drainage) rate between subsequent measurements.

[16] The dissipation rate $k_{i}\left[\mathrm{~T}^{-1}\right]$ due to leaching was calculated as

$$
k_{i}=\frac{1}{\Delta t_{i}} \ln \left(\frac{\mathrm{M}_{0}-\mathrm{M}_{i-1}}{\mathrm{M}_{0}-\mathrm{M}_{i}}\right)
$$

where $\ln$ denotes the natural logarithm, $\mathrm{M}_{0}[\mathrm{M}]$ the applied mass, $\mathrm{M}_{i}[\mathrm{M}]$ the site averaged cumulative mass of solute measured in the leachate at time $t_{i}=t_{i-1}+\Delta t_{i}[\mathrm{~T}]$, and $\Delta t_{i}$ [T] the time between the consecutive measurements. For drainage $k_{i}=\left(D_{i}-D_{i-1}\right) / \Delta t_{i}$ where the units of $k_{i}$ are now [ $\left.\mathrm{L} \mathrm{T}^{-1}\right]$, and $D_{i}[\mathrm{~L}]$ is the cumulative drainage at time $t_{i}$. The average dissipation (drainage) rate $\bar{k}_{j}\left[\mathrm{~T}^{-1}\right]$ of regime $j$ was calculated by linear regression (see Table S4 in the auxiliary material). These variables are denoted $\bar{D}, \overline{\mathrm{Br}}, \overline{\mathrm{MBT}}$ and $\overline{\text { ETD }}$ for drainage, $\mathrm{Br}^{-}, \mathrm{MBT}$ and ETD, respectively. Three data points were excluded from the linear regressions, however all points were considered in terms of deviations from the linear trends. Those points excluded from regressions caused significantly poorer linear correlation when included. They are interpreted here as part of short transitional phases between two clearly distinct regimes, and possibly a third which existed at the beginning of the experiment. These data and the initial point are shown in Figure 3 as open diamonds.

[17] The difference between short time scale $\left(k_{i}\right)$ and regime average $\left(\bar{k}_{j}\right)$ rates, including all data, were then normalized by the maximum difference across all measurements, to derive the normalized regime deviation $k_{i}^{*}[-]$, i.e.,

$$
k_{i}^{*}=\left(k_{i}-\bar{k}_{j}\right) / \max _{\forall\{i, j\}}\left(k_{i}-\bar{k}_{j}\right)
$$

Positive values of $k^{*}$ indicate a dissipation (drainage) rate above the regime average rate, $k^{*}{ }_{i}<0$ indicate below regime average fluxes and values near zero indicate the flux was close to the average flux in the regime. This variable helps us to interpret the short-term fluctuations in drainage $\left(D^{*}\right)$ and leaching $\left(\mathrm{Br}^{*}, \mathrm{MBT}^{*}\right.$ and $\left.\mathrm{ETD}^{*}\right)$, filtering out the effect of regime behavior on leaching. The following describes the rainfall variables considered for comparison.

\subsection{Data Preparation: Climate Variables}

[18] Storm properties and a variety of rainfall resolutiondependent statistics were adopted for the multivariate analysis. Storms were identified from the data as rainfall records for which there was a minimum of $7 \mathrm{~h}$ of no rain between two rainfall recordings, irrespective of its intensity [Robinson and Sivapalan, 1997]. Storms are characterized by an average intensity $S_{\mathrm{i}}\left[\mathrm{L} \mathrm{T}^{-1}\right]$, a depth $S_{\mathrm{h}}[\mathrm{L}]$ and a duration $S_{\mathrm{r}}$ [T]. The interstorm period $S_{\mathrm{b}}$ [T] is the time between successive storms. An interstorm or a storm traversing two sampling intervals was truncated at midday of the day of sampling. We also considered the rainfall intensity at daily $P_{24}\left[\mathrm{~L} \mathrm{~T}^{-1}\right]$, hourly $P_{60}\left[\mathrm{~L} \mathrm{~T}^{-1}\right]$ and $10 \mathrm{~min} P_{10}\left[\mathrm{~L} \mathrm{~T}^{-1}\right]$ resolution. Given our hypothesis of the various rainfall controls, described in the Introduction, we chose only the maximum $\left(\hat{S}_{\mathrm{i}}, \hat{S}_{\mathrm{r}}, \hat{S}_{\mathrm{h}}, \hat{S}_{\mathrm{b}}, \hat{P}_{24}, \hat{P}_{60}, \hat{P}_{10}\right)$ and the mean $\left(\bar{S}_{\mathrm{i}}, \bar{S}_{\mathrm{r}}\right.$, $\left.\bar{S}_{\mathrm{h}}, \bar{S}_{\mathrm{b}}, \bar{P}_{24}, \bar{P}_{60}, \bar{P}_{10}\right)$ rainfall statistics for each sampling interval for analysis. Finally, the average rainfall $\bar{P}\left[\mathrm{~L} \mathrm{~T}^{-1}\right]$ and potential evaporation $\overline{E p}\left[\mathrm{~L} \mathrm{~T}^{-1}\right]$ during each sampling interval define the climatic water balance $\overline{W B}=\bar{P}-\overline{E p}$ $\left[\mathrm{L} \mathrm{T}^{-1}\right]$. The climate variables extracted for analysis are statistics derived from the same period during which the leachate sample was collected. Therefore the temporal resolution of sampling matches the variables chosen for analysis even if the scale of data comprising each statistic varies.

\subsection{Statistical Methods}

[19] Classification and regression tree (CART) analysis is a nonparametric statistical method for explaining a how a response variable, either categorical (classification) or numeric (regression), is related to one or more predictor variables [Breiman et al., 1984; Venables and Ripley, 1994]. CART was used here to identify the dominant rainfall controls on dissipation and drainage rates, therefore all predictor variables and explanatory variables are numeric values. A regression tree is generated by hierarchically splitting the data based on a simple rule defined by one explanatory variable at each split. In this case data are partitioned into one of two groups depending upon whether 

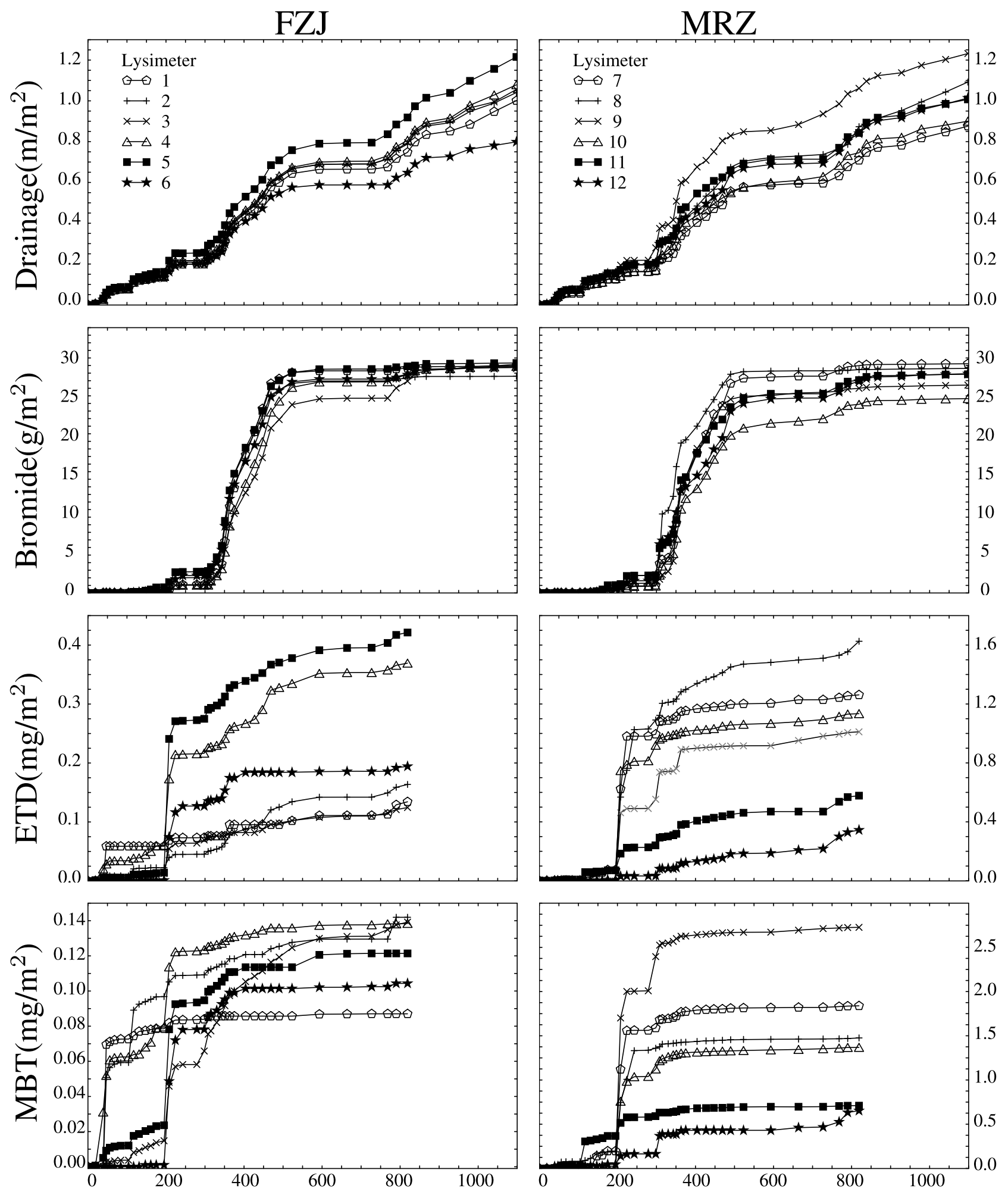

\section{Time since application (days)}

Figure 2. Cumulative amounts of water and solutes in leachate in each of the 12 lysimeters at Forschungszentrum Jülich (FZJ) and Merzenhausen (MRZ). Plot symbols correspond to different lysimeters at each site. To make the plots clearer, some data were scaled. For lysimeter 4 the mass was reduced by $1 / 6$ for ETD and 1/3 for MBT; the MBT mass for lysimeter 9 has been multiplied by 1/5; and for lysimeter 12 the MBT mass was multiplied by 10 . 
(a)

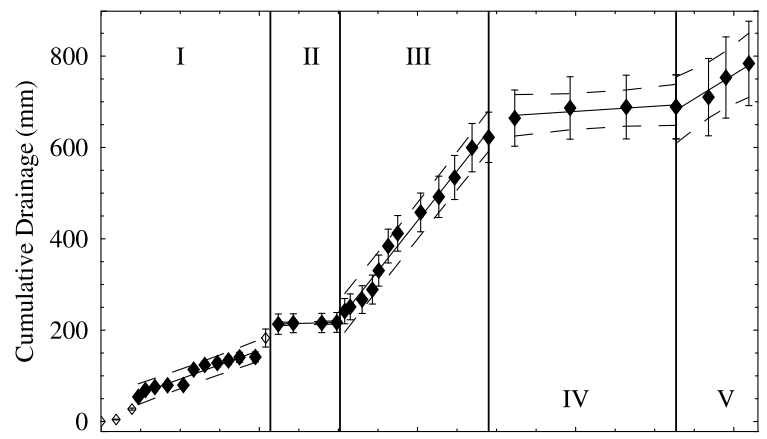

(b)

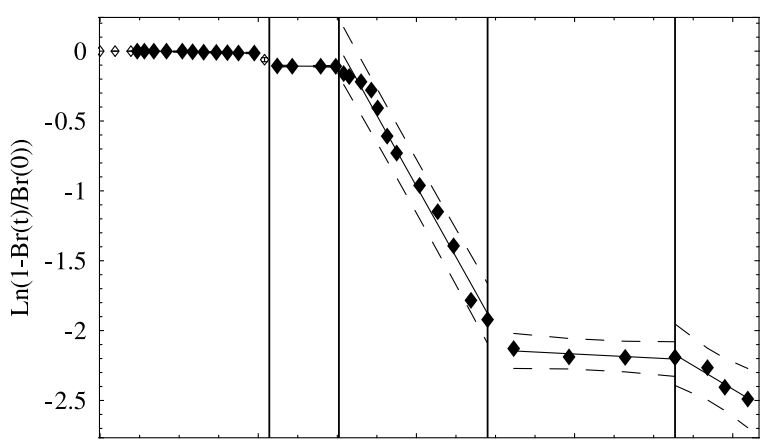

(c)
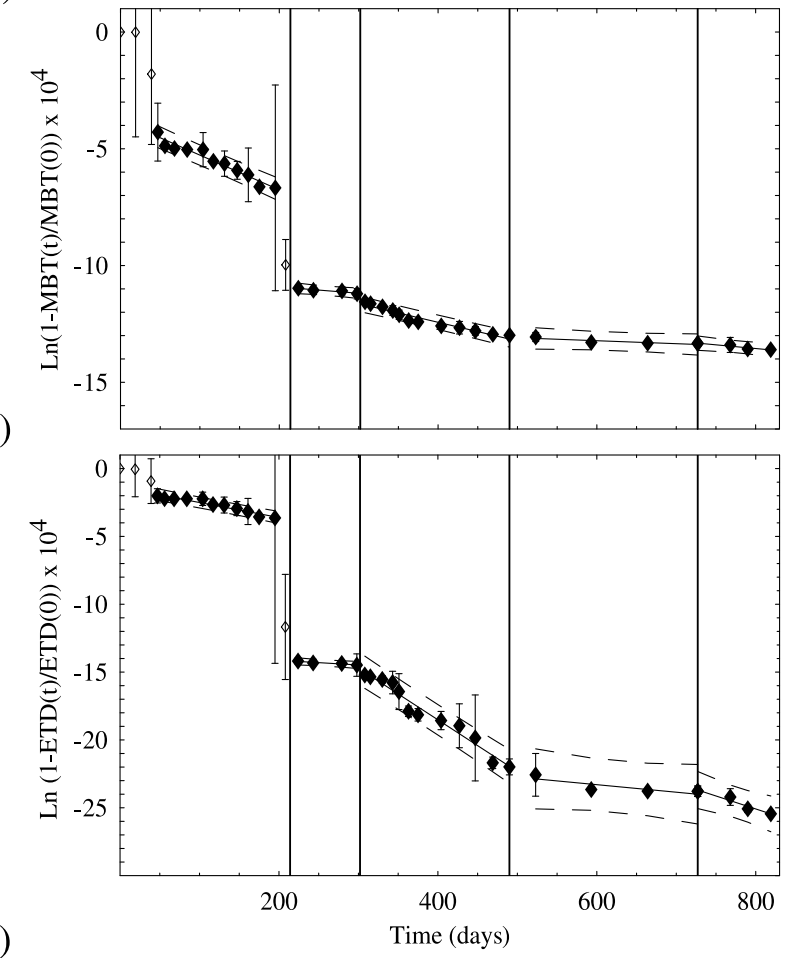

Figure 3. Regime behavior of site averaged (a) cumulative drainage, (b) bromide, (c) MBT, and (d) ETD dissipation at FZJ. Vertical lines separate regimes, denoted by the Roman numerals. Diamonds denote the site average; error bars show the $95 \%$ confidence interval about the mean; solid lines are the linear regressions; and dashed lines are the standard error of the estimate.

a chosen explanatory variable is less than or greater than a threshold value. The choice of split to use at each level in the tree is determined by an exhaustive search of possible splits, which maximizes the improvement in a goodness of fit measure [Venables and Ripley, 1994; Nolan et al., 2008].
In our case we use the mean squared difference of the response variable from its mean in each split, the so-called deviance, as the goodness of fit measure [Breiman et al., 1984; Qian and Anderson, 1999]. A tree can be grown until each leaf of the tree contains only one data point (and zero deviance) or a minimum split size (we chose to use a minimum of five data), however leaving the analysis here results in a complex tree model which tends to over fit the data. To overcome this, $v$-fold cross validation is used to effectively prune branches in order to find a minimal tree, more robust to noise in the data. This procedure assesses how well the tree performs on subsamples of the data used to grow the tree, and is useful when the data set is not very large [Breiman et al., 1984]. We used tenfold cross validation which randomly splits the data set into 10 , approximately evenly sized groups. One of these groups is then removed and the remaining nine groups are passed through the tree, allowing the calculation of the sample deviance at each split. This procedure is repeated giving an average deviance at each split. From this the tree size can be selected automatically as the smallest hierarchy of splits whose total average deviance is within one standard error of the of deviances of the tree size with the minimum average deviance [Breiman et al., 1984]. The software SPlus version 6.1 was used for the analysis [Venables and Ripley, 1994; Insightful Corporation, 2005]. The auxiliary material shows the results of the cross validation leading to the choice of the tree sizes for each analysis (Figure S1). Figure 4 illustrates how to interpret the regression trees presented.

\section{Results and Discussion}

\subsection{Exploratory Data Analysis}

[20] Rainfall properties appear to change throughout the year. For example, summer and spring rainfall events ( days 100-300 and 500-700) are less regular and much more intense than autumn and winter rainfall which occurs frequently and at generally lower intensities (Figure 1). There is also a clear difference displayed in the rainfall intensity with a change in temporal scale. The highest intensities are observed at the $10 \mathrm{~min}$ measurement resolution.

[21] $\mathrm{Br}^{-}, \mathrm{MBT}$, and ETD were detected in the first leachate sampling event, 19 days after application (Figure 2). Such a rapid breakthrough suggests that preferential flow was responsible [Pütz et al., 1998; Dressel, 2003]. This is supported by modeling [Kasteel et al., 2006] which identified that as much as $30 \%$ of drainage occurred as rapid preferential flow in this soil. While all solutes were transported equally fast initially, there are clear differences in their transport behavior. Overall, $\mathrm{Br}^{-}$displays a smoother breakthrough curve (see Figure 2). The herbicides on the other hand display more episodic leaching.

[22] In fact, only four of the largest leaching measurements, on days 47, 108, 208 and 224, accounted for between $63.1 \%$ (MBT) and $49.2 \%$ (ETD), of the total herbicide mass leached during the experiment. These same four samples accounted for only $9.3 \%$ of the total $\mathrm{Br}^{-}$mass leached. These fractions are in the same order as the strength of adsorption to soil, thus supporting our hypothesis, that the significance of rapid transport is greater for more strongly sorbing substances. This is further supported by the break- 


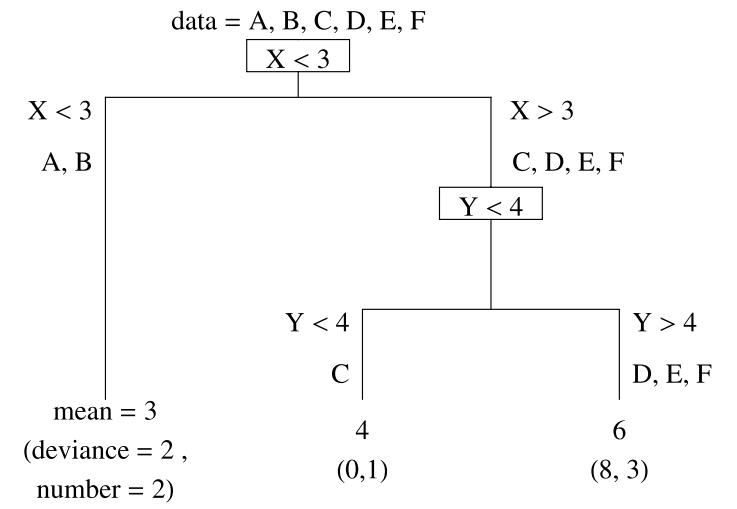

\begin{tabular}{c|cccc|ccc}
\hline Data & \multicolumn{2}{|c|}{ Predictor } & Response & \multicolumn{4}{c}{ Tree result } \\
\cline { 6 - 8 } Label & \multicolumn{2}{|c}{ variables } & variable & Number & Mean & Deviance \\
& $\mathrm{W}$ & $\mathrm{X}$ & $\mathrm{Y}$ & $\mathrm{Z}$ & of data & & \\
\hline $\mathrm{A}$ & 0 & 1 & 4 & 2 & 2 & 3 & 2 \\
$\mathrm{~B}$ & 3 & 2 & 2 & 4 & & & \multirow{2}{*}{2} \\
\hline $\mathrm{C}$ & 5 & 3 & 3 & 4 & 1 & 4 & 0 \\
\hline $\mathrm{D}$ & 1 & 4 & 4 & 8 & 3 & 6 & \multirow{2}{*}{8} \\
$\mathrm{E}$ & 2 & 5 & 4 & 4 & & & \\
$\mathrm{~F}$ & 0 & 6 & 6 & 6 & & & \\
\hline
\end{tabular}

(deviance $=2$,

Figure 4. An example regression tree to predict the response variable $Z$ from a multivariate data set comprising the predictor variables $W, X, Y$, and $Z$. Variable $W$ was not used to develop the tree or was trimmed during cross validation. All the data points, A, B, C, D, E, and F enter the tree at the top. Data A and $\mathrm{B}$ which satisfy the condition that $X<3$ are partitioned to the left, and those that do not are partitioned to the right. This partitioning is continued through to the end of the tree. Shown at the end of each branch is the predicted value of $Z$, i.e., the mean of the $Z$ values at that point, the sum of squared difference from the mean, the deviance, and the number of data points reaching the terminus.

through curves which suggest little additional chemical is expected to be leached beyond the end of the experiment.

[23] The largest herbicide transport event for most lysimeters was observed in the sample collected on day 208. Just prior to this the largest hourly $\left(17 \mathrm{~mm} \mathrm{~h}^{-1}\right.$ at MRZ) and $10 \mathrm{~min}\left(85 \mathrm{~mm} \mathrm{~h}^{-1}\right.$ at MRZ) rainfall intensities for the experiment were recorded at both sites (see Figure 1). This is consistent with observations that the greatest transport occurs as a result of the most significant rainfall event in the period after application [Kladivko et al., 2001].

[24] However, 208 days is a significant amount of time since application, and one would expect most of the $\mathrm{Br}^{-}$to have moved well below the soil surface by then. So could the presence of a subsurface plough layer be responsible for the large herbicide and bromide transport at this time? The significance of earlier preferential flow events (days 47 and 108) and the soil data (see Table S1 in the auxiliary material) do not support this hypothesis. Additionally, modeling by Dressel [2003] suggests that, in the absence of preferential flow, the bromide concentration in outflow was coincidentally, expected to increase significantly around day 200 . Therefore, significant exchange between mobile and immobile regions of the soil as a result of the large input of water at this time, along with the imminent breakthrough of bromide that has largely moved slowly through the soil matrix, can explain the large flux of bromide at this time.

[25] Cumulative drainage and bromide transport were similar both within $(p<0.01)$ and between $(p<0.01)$ sites (see also Figure 2). In contrast there was greater within site variability for herbicides in comparison to $\mathrm{Br}^{-}$transport. There was also a significant $(p<0.01)$ difference in the mean amount of herbicides leached between sites. This further emphasizes the limitations of solute flux prediction given that the soil from all 12 lysimeters was originally collected from the same field. Within and between site differences in solute leaching and applications are summarized in the auxiliary material (Table S3). The greater variability of herbicide transport within a site may be due to heterogeneity of fast transport pathways and soil chemical properties [Allaire et al., 2002; Muller et al., 2003].
[26] When considering the site averaged behavior, there were five distinct periods, regimes, during which the drainage rate was approximately constant (Figure 3 ). There were also rapid transitions between these regimes (Figure 3a). The transitions are expected to result from the episodic propagation of near surface boundary conditions through the wetting profile. For example, most of the variability at the upper boundary is buffered, leading to only small variations in water content at the lower boundary, which in turn controls the outflow in the lysimeter. Occasionally a sufficiently large perturbation propagates to depth to establish a new water content in the unit gradient zone and hence a new flux. While seasonality is clearly a control it is interesting that the regimes occur for a little as a month and longer than three months, that the transitions are relatively rapid, and the drainage flux is so stable. This regime behavior was reproduced by an uncalibrated HYDRUS 1D [Simunek et al., 1998] simulation (see Figure S2 in the auxiliary material). It has also been observed previously at a large $4 \mathrm{~m}$ deep, sandy, free draining lysimeter located at Colbitz, Germany [Struthers et al., 2003], suggesting it is a more general phenomena than previously recognized.

[27] The solutes display a similar pattern, with log linear regimes matching each of the drainage regimes (Figure 3 ). The average drainage and dissipation rates for each of these five regimes is summarized in the auxiliary material (Table S4). It is also apparent that herbicide transport is significantly affected by a small number of large leaching events causing large deviations from the regime dynamic, and to a much lesser degree $\mathrm{Br}^{-}$and drainage. It is these deviations from the regimes that we will exploit to derive short-term fluctuations in leaching, so that we can filter out the effect of seasonality and ongoing chemical degradation.

[28] While lysimeters provide well defined boundaries for flux calculation, they do suffer some limitations. Modeling by Abdou and Flury [2004] showed that mobile solutes such as bromide may actually move slower and disperse less in lysimeters which developed a significant saturated zone in comparison to their field counterparts. The lower boundary in a lysimeter will tend to keep the soil wetter, 


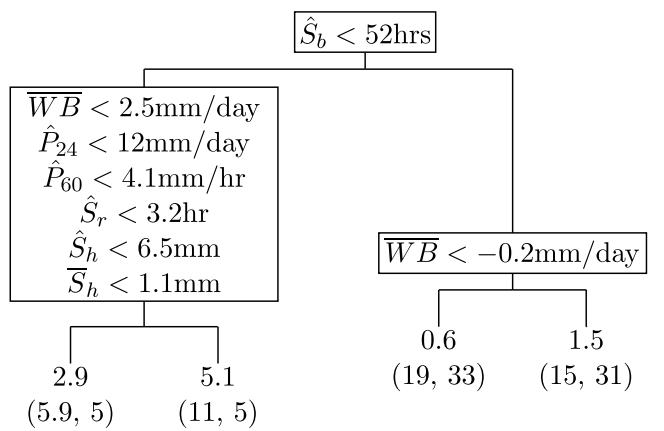

(a) $\bar{D}$

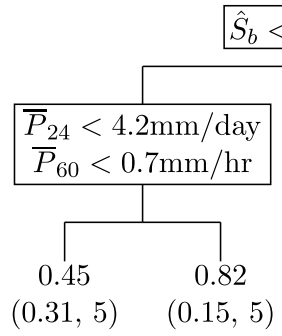

$(0.11,5)$
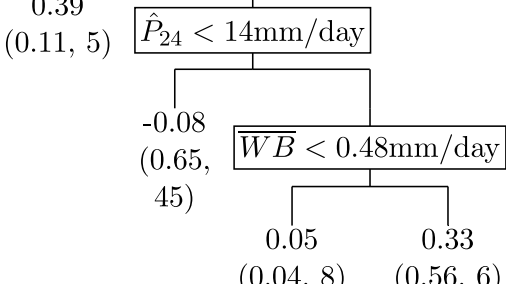

(b) $D^{*}$

Figure 5. Regression trees for drainage to predict (a) sample interval drainage rate $\bar{D}$ and (b) normalized difference between sample interval and regime average drainage rate $D^{*}$.

throughout the profile, thus reducing the potential for exchange between preferential flow pathways and the soil matrix during rapid transport. Therefore, we expect that preferential transport would actually be moderately enhanced in a lysimeter in comparison to a corresponding field soil, with a deep water table.

[29] Also, in relation to the lower boundary, does significant mixing occur in the near saturated zone and does this explain the transport regimes? First we note that the regimes are evident very early after the experiment commenced, and before a "lower mixing zone" would have any significant amount of chemical to mix. One fully mixed inflow-outflow cell, with an initial concentration and no further inputs, would ideally lead to an exponential decay as observed. It is well established that for pesticides such a mixing zone occurs near the soil surface [Ahuja et al., 1981; Steenhuis et al., 1994]. Therefore, if the lower boundary is also acting as a significant mixing zone for the herbicides, we would expect the system to behave like two tanks in series, which would not be expected to produce the observed log linear behavior. We anticipate that solute mass exchange between mobile and immobile regions in the unsaturated zone is correlated with the bulk water content, which in turn is related to the drainage regimes. Further work is required to verify this, but we would like to reiterate that our focus in this paper is to exploit the regimes in order to evaluate short-term fluctuations in leaching.

\subsection{Regression Tree Analysis}

\subsubsection{Drainage}

[30] With a maximum interstorm duration $\hat{S}_{\mathrm{b}}<52 \mathrm{~h}, \bar{D}$ drainage rates are predicted to be large at $4.0 \mathrm{~mm} \mathrm{~d}^{-1}$ (Figure 5). In addition to the principal split identified by the CART analysis, we can also assess the role of other potential splits that were omitted. Where other splits have a similar deviance then they may have been excluded just by chance due to the limited size of the data. An evaluation of possible alternative principal splits revealed that a positive climatic water balance of $\overline{W B}>2.2 \mathrm{~mm} \mathrm{~d}^{-1}$, provided a similar partitioning of the data.

[31] With the condition that $\hat{S}_{\mathrm{b}}<52 \mathrm{~h}$, a number of secondary criteria split the resulting data equally well. This occurred in part because of the size of the data set, but due also to the nature of the storms occurring when the largest drainage rates were observed. These criteria consist of relatively high maximum daily and hourly rainfall intensities, maximum storm duration, maximum storm depth, mean storm depth as well as a large and positive climatic water balance. Where all these variables were exceeded the greatest drainage rates were predicted $\left(\bar{D}=5.1 \mathrm{~mm} \mathrm{~d}^{-1}\right)$. When $\hat{S}_{\mathrm{b}}>52 \mathrm{~h}$ the drainage rate was predicted to be $\bar{D}=$ $1.0 \mathrm{~mm} \mathrm{~d}^{-1}$. For these data the climatic water balance was a dominant control on the drainage rate with $\overline{W B}<-0.2 \mathrm{~mm}$ $\mathrm{d}^{-1}$ predicting $\bar{D}=0.6 \mathrm{~mm} \mathrm{~d}^{-1}$ and $\bar{D}=1.5 \mathrm{~mm} \mathrm{~d}^{-1}$ otherwise. While the temporal resolution of sampling was coarser than the rainfall resolution we may interpret that the largest drainage measurements $\left(\bar{D}=5.1 \mathrm{~mm} \mathrm{~d}^{-1}\right)$ were likely caused by a single large rainfall event $\left(\hat{P}_{60}>4.1 \mathrm{~mm}\right.$ $\mathrm{h}^{-1}$ and $\hat{P}_{24}>12 \mathrm{~mm} \mathrm{~d}^{-1}$ ) in each sampling period, occurring on wet soils, as suggested by $\overline{W B}>2.5 \mathrm{~mm} \mathrm{~d}^{-1}$.

[32] The regression tree to predict $D^{*}$ (Figure $5 \mathrm{~b}$ ) appears quite similar to that derived for $\bar{D}$ (Figure 5a). When $\hat{S}_{\mathrm{b}}<52 \mathrm{~h}$ and the average daily $\left(\bar{P}_{24}<4.2 \mathrm{~mm} \mathrm{~d}^{-1}\right)$ and hourly $\left(\bar{P}_{60}<0.7 \mathrm{~mm} \mathrm{~h}^{-1}\right)$ rainfall intensity are low, the normalized regime deviation $D^{*}$ is predicted to be 0.45 , indicating relatively large, above regime average fluxes. When these mean rainfall intensities were greater, the normalized regime deviation was predicted to be greater $\left(D^{*}=0.82\right)$. With $\hat{S}_{\mathrm{b}}>52 \mathrm{~h}$ and a short average time between storms $\bar{S}_{\mathrm{b}}<9.3 \mathrm{~h}$, the normalized regime deviation was again large $\left(D^{*}=0.39\right)$. With longer mean times between storms, $D^{*}$ was also large when the maximum daily rainfall intensity was high $\left(\hat{P}_{24}>14 \mathrm{~mm} \mathrm{~d}^{-1}\right)$ and coincided with a positive climatic water balance $\left(\overline{W B}>0.48 \mathrm{~mm} \mathrm{~d}^{-1}\right)$. Where these conditions are not met $D^{*}$ was near zero indicating close to regime average drainage rates.

[33] These results suggest a soil moisture control on short-term large drainage rates [Heppell et al., 2002]. For example, large $D^{*}$ occur when there is greater average rainfall on wet soil, which is likely when $\overline{W B}$ is large and $\bar{S}_{\mathrm{b}}$ is small. However, when storms occur less frequently, surface soils are likely to be drier resulting in the need for large rain event $\left(\hat{P}_{24}>14 \mathrm{~mm} \mathrm{~d}^{-1}\right)$ to overcome this water limitation. If soils are too dry, as suggested by a small $\overline{W B}$, then none of the rain days above $\hat{P}_{24}>14 \mathrm{~mm} \mathrm{~d}^{-1}$ were sufficient to trigger rapid drainage.

\subsubsection{Bromide}

[34] The regression tree to predict $\overline{\mathrm{Br}}$ dissipation rates (Figure 6a) appears to reflect the timing of the breakthrough 


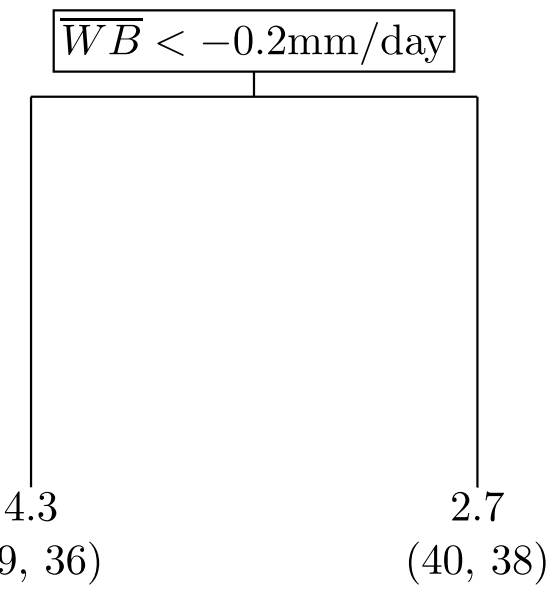

(a) $\overline{\mathrm{Br}}$

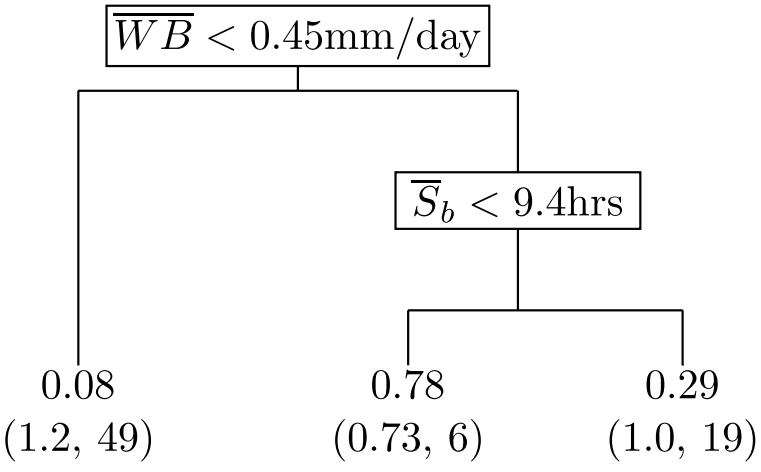

(b) $\mathrm{Br}^{*}$

Figure 6. Regression tree analysis of rainfall controls on bromide leaching to predict (a) sample interval bromide dissipation rates $\overline{\mathrm{Br}}$ and (b) normalized difference between sample interval and regime average bromide dissipation rate $\mathrm{Br}^{*}$.

of the tracer. A single split in the data was identified after cross validation, and this split corresponds approximately to the climatic water balance of regime III during which most of the leaching occurred. Large $\overline{\mathrm{Br}}$ is associated with a larger positive climatic water balance. By considering instead the short-term fluctuations, the normalized regime deviation $\mathrm{Br}^{*}$ (Figure 6b), partially removes this effect. The principal split in the data is now given by $\overline{W B}<0.45 \mathrm{~mm}$ $\mathrm{d}^{-1}$ (the majority of data) where $\mathrm{Br}^{*}$ are close to zero and hence the bromide leaching is predicted to be near the regime average. When there was large positive climatic water balance $\overline{W B}>0.45 \mathrm{~mm} \mathrm{~d}^{-1}, \mathrm{Br}^{*}$ was large and $\mathrm{Br}^{*}$ was greater still if there was a short mean time between storms $\bar{S}_{\mathrm{b}}<9.3 \mathrm{~h}$. This is similar to the $\bar{S}_{\mathrm{b}}<9.4 \mathrm{~h}$ criterion which occurred in the $D^{*}$ regression tree, also predicting greater normalized regime deviations.

\subsubsection{Herbicides}

[35] The CART analyses of herbicide leachate rates and normalized regime deviations produced identical trees, therefore for brevity regression trees are presented for

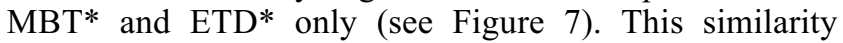
suggests that the pulsed transport of herbicides is so dominant it is being pickup by both analyses.

[36] A maximum storm depth of $\hat{S}_{\mathrm{h}}>19 \mathrm{~mm}$ was found to be the first split in the trees for both MBT and ETD and predicted the largest deviations $\left(\mathrm{MBT}^{*}=0.4\right.$ and $\mathrm{ETD}^{*}=$ $0.5)$. Therefore, a single storm in the two week to two month sampling interval dominated the largest herbicide leaching events. It was decided to check if this split may have occurred as a result of chance and whether there were alternative splits which could provide similar predictions. An evaluation of these other potential splits (see Table S5 in the auxiliary material), which were very similar for MBT* and ETD* (not shown), indicated large average and coarse temporal resolution rainfall statistics lead to similar predictions. These larger average rainfalls were also found to occur along with large maximum storm depths in many sampling periods with greater amounts of herbicide leaching. As a result it is considered that both wet soils in conjunction with a large storm event contributed to the largest leaching events. The same control, i.e., a large

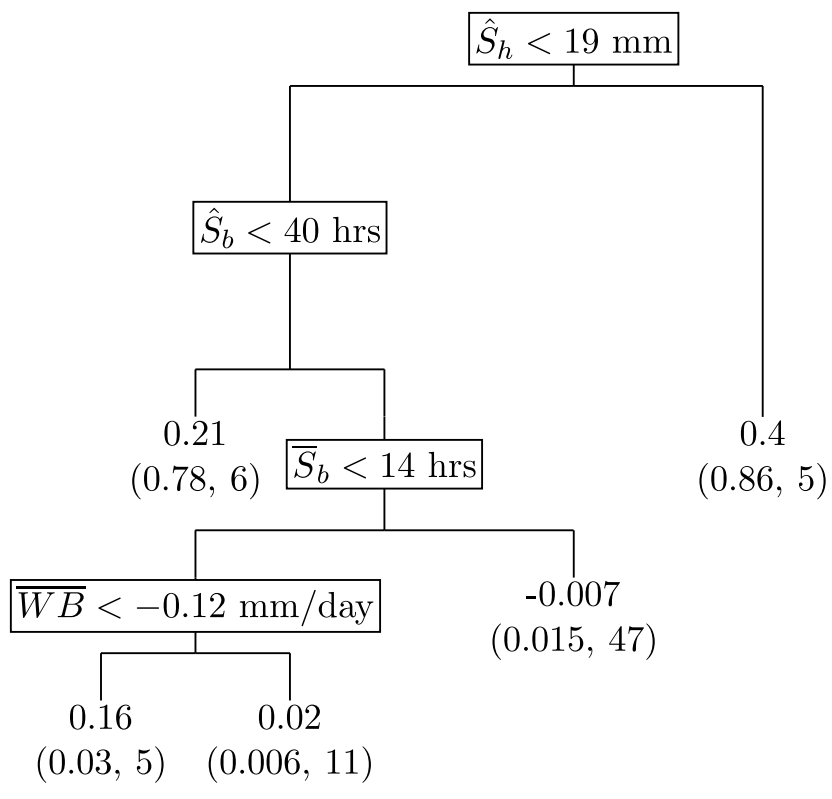

(a) $\mathrm{MBT}^{*}$

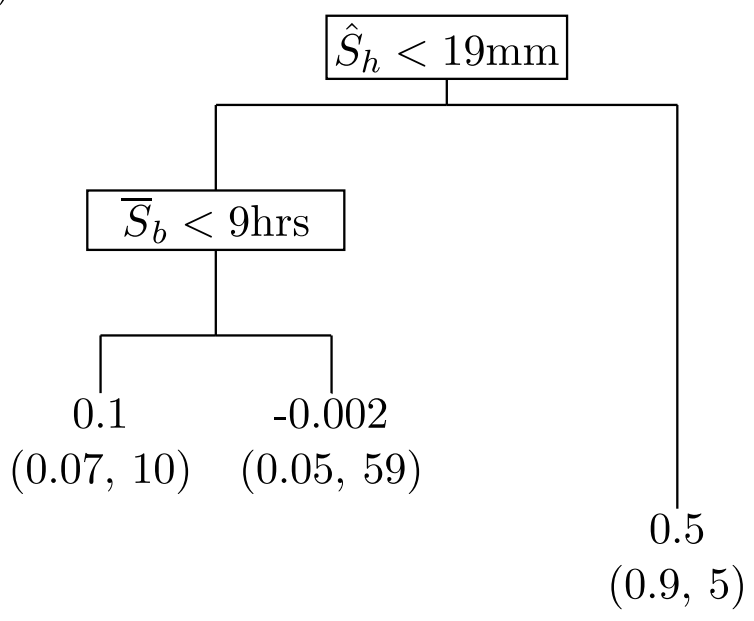

(b) $\mathrm{ETD}^{*}$

Figure 7. Regression tree analysis of rainfall controls on herbicide leaching. Regression trees predict the normalized difference between sample interval and regime average dissipation rates for the herbicides (a) $\mathrm{MBT}^{*}$ and (b) ETD*. 


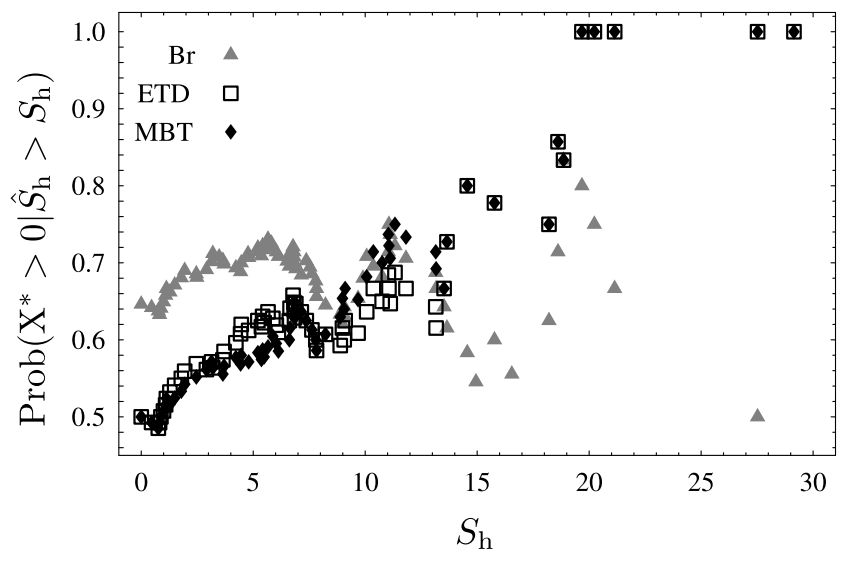

Figure 8. Probability of rapid leaching (i.e., $X^{*}>0$, where $X^{*}$ denotes $\mathrm{Br}^{*}, \mathrm{ETD}^{*}$, or $\left.\mathrm{MBT}^{*}\right)$, given that the maximum storm depth $\hat{S}_{\mathrm{h}}$ is greater than $S_{\mathrm{h}}$.

rainfall event on wet soils, has also been previously identified for glyphosate leaching [Vereecken, 2005].

[37] For the more strongly sorbing chemical, MBT, a maximum time between storms $\hat{S}_{\mathrm{b}}<40 \mathrm{~h}$ predicts $\mathrm{MBT}^{*}=$ 0.21 (Figure 7a). In a similar way to drainage, a greater maximum interstorm time $\hat{S}_{\mathrm{b}}>40 \mathrm{~h}$, but with more frequent storms on average $\bar{S}_{\mathrm{b}}<14 \mathrm{~h}$, predicts above regime average dissipation rates. When storms occur frequently however, a negative climatic water balance $\overline{W B}<-0.12 \mathrm{~mm} \mathrm{~d}^{-1}$ predicts higher MBT*. The criteria leading to this suggest that the negative climatic water balance represents stormy summer rainfall and this is supported by an examination of these data. Additionally, they displayed relatively large maximum $10 \mathrm{~min}$ rainfall intensities or in one instance a maximum storm depth of $18 \mathrm{~mm}$.

[38] For ETD (see Figure 7b), the second split in the tree was $\bar{S}_{\mathrm{b}}<9 \mathrm{~h}$, and in a similar way to the trees for $D^{*}$ and $\mathrm{Br}^{*}$, predicted ETD* to be larger when the mean interstorm period was short. When $\bar{S}_{\mathrm{b}}>9 \mathrm{~h}$, as is the case for the majority of data, ETD* was close to the regime average.

[39] In a similar fashion to the results for drainage, the regression trees for herbicide transport suggest a soil moisture control on leaching for less frequent lower-intensity storms. The largest leaching events occur when an extreme storm occurs on wet soils, as suggested by the high average rainfall of the alternative splits (refer to Table S5 in the auxiliary material) which after inspection comprise largely the same data. These events were not limited by soil moisture. When storm events are smaller, more frequent storms promote herbicide leaching, suggesting event magnitude is limiting to transport. Finally when both storm magnitude and soil moisture are limiting herbicide leaching follows the regime behavior. This classification is similar to that derived by Heppell et al. [2002] in the context of preferential flow.

\subsubsection{Evaluating a Rainfall Event Threshold}

[40] The $19 \mathrm{~mm}$ maximum storm depth, as identified in the regression tree analysis for herbicide leaching, predicts the timing of between $10 \%$ (FZJ) and 17\% (MRZ) of above regime average leaching events for both MBT and ETD. Despite this however, at the MRZ site the threshold accounted for 55\% (MBT) and 56\% (ETD) of the total amounts of herbicides leached, while at FZJ the amounts were lower at 40\% (MBT) and 38\% (ETD). In contrast this threshold only accounted for between 1\% (FZJ) and 10\% (MRZ) of the total bromide leached.

[41] On the basis of our results it is reasonable to expect that as the magnitude of the rainfall event increases, we can be more confident that rapid pesticide leaching occurs, because soil moisture becomes less limiting. This can be seen in a plot of the probability that a leaching period is above regime average, conditional on the magnitude of the largest storm $\hat{S}_{\mathrm{h}}$ (see Figure 8 ). This probability $\operatorname{Prob}\left(X^{*}>\right.$ $\left.0 \mid \hat{S}_{\mathrm{h}}>S_{\mathrm{h}}\right)$, where $X$ denotes $\mathrm{Br}$, ETD or MBT, was estimated from those data which satisfied the condition that $\hat{S}_{\mathrm{h}}>S_{\mathrm{h}}$ as the fraction of leaching measurements whose regime normalized deviation $X^{*}$ was greater than zero, i.e., displayed above the regime average leaching behavior.

[42] It can be seen that as $\hat{S}_{\mathrm{h}}$ increases the conditional probability of above regime average leaching increases for both pesticides, whereas it remains nearly constant for bromide. The greater fluctuations with increasing maximum storm depth is a result of the limited number of events with large maximum storm depths. Significant $(p<0.01)$ increasing trends were found for both pesticides while the trend for bromide was not significantly different from zero. Again, the reason for this appears to be that strong sorption causes pesticides to be available in the soil surface where they can be influenced by short-term, but significant, rainfall events. Bromide on the other hand, is rapidly transported away from the surface and is subject instead to the influence of a buffered rainfall input. The gradual increase in the probability of rapid leaching with increasing maximum storm depth for the pesticides suggests that other rainfall characteristics, such as storm duration and intensity also play a role in rapid transport, particularly when storms are smaller. In systems where soil moisture fluctuations are likely to be more significant a simple storm depth threshold might not be sufficient. Instead a more sophisticated combination of rainfall frequency, intensity, duration and withinstorm characteristics may be required [Heppell et al., 2002; McGrath et al., 2007].

\section{Potential Approaches to Frequentist Risk Assessment}

[43] The above results indicate that significant pesticide transport by preferential flow is associated with the occurrence of a threshold storm depth. Therefore existing rainfall data could be used to assess the timing and frequency of rapid herbicide transport events. Where rain data are available at sufficient resolution to define these events this should be straight forward to do. Alternatively, with the use of empirical or physical climate models, downscaling methods could be employed.

[44] However, there were also indications that rainfall intensity, duration and frequency were important too. Triggering of rapid preferential flow by the limited ability of the surface soil matrix (as opposed to the entire soil including macropores) to fully infiltrate precipitation is likely to be the primary and more general mechanism of enhanced leaching events [Beven and Germann, 1982; Edwards et al., 1992]. Mobilization of colloids and resulting facilitative transport as a result of high-intensity rainfall and/or changes to soil 
chemistry may be another [Flury, 1996; de Jonge et al., 2004].

[45] One possible way to tackle the first of these mechanisms is to use an infiltration model to simulate the occurrence and magnitude of macropore flow events [Struthers et al., 2007; McGrath et al., 2007]. This would allow quantification of the frequency of rapid leaching events at sites where leaching data are unavailable. With such a model, macropore flow magnitude-frequency relationships for particular soil-climate systems could be established. This may be one way to begin to quantify leaching risk without the added uncertainty of complex simulations of flow and solute transport of the entire unsaturated zone.

\section{Conclusions}

[46] A careful analysis of a 3 year lysimeter leaching experiment has revealed, at a coarse scale, regime behavior of water flow and solute transport. This is evidence of a soil-climate system which behaves as a linear system with threshold switching between stable states. The water flow regimes are to be expected based upon unsaturated flow theory, however a better understanding of the circumstances required for this behavior to be observed requires more research.

[47] We exploited these regimes to determine the shortterm fluctuations in transport and to assess what climate variables are responsible. We found that a threshold storm depth predicted the occurrence of significant rapid herbicide transport, whereas a more coarse scale water balance predicted water flow and bromide transport. The results also suggest greater rain event frequency promotes preferential transport when storms are smaller in magnitude.

[48] In this system at least, the historical occurrence of rain events in excess of $19 \mathrm{~mm}$ can be used to assess the timing and frequency of rapid herbicide transport events. Alternatively, with the use of an infiltration model we may be able to better quantify when and how often different soilclimate systems are likely to experience rapid pesticide leaching [Struthers et al., 2007; McGrath et al., 2007].

[49] Acknowledgments. The first author would like to acknowledge financial support from German Academic Exchange Service (DAAD), Centre for Groundwater Studies, Postgraduate Research School of the University of Western Australia, Water Corporation of Western Australia, and Australian Research Council's Linkage Projects funding scheme (project LP0211883).

\section{References}

Abdou, H. M., and M. Flury (2004), Simulation of water flow and solute transport in free-drainage lysimeters and field soils with heterogeneous structures, Eur. J. Soil Sci., 55, 229-241.

Ahuja, L., A. Sharpley, M. Yamamoto, and R. Menzel (1981), The depth of rainfall-runoff-soil interactions as determined by ${ }^{32} \mathrm{P}$, Water Resour. Res., 17(4), 969-974, doi:10.1029/WR017i004p00969.

Allaire, S. E., S. C. Gupta, J. Nieber, and J. F. Moncrief (2002), Role of macropore continuity and tortuosity on solute transport in soils: 1 . Effects of initial and boundary conditions, J. Contam. Hydrol., 58(3-4), 299321, doi:10.1016/S0169-7722(02)00035-9.

Baez, M. E., M. Rodriguez, P. Vilches, and E. Romero (2001), Adsorption of methabenzthiazuron on six allophanic and nonallophanic soils: Effect of organic matter amendment, J. Environ. Sci. Health B, 36(1), 95-105, doi:10.1081/PFC-100000920.

Beven, K., and P. Germann (1982), Macropores and water flow in soils, Water Resour. Res., 18(5), 1311-1325, doi:10.1029/WR018i005p01311.

Breiman, L., J. H. Friedman, R. A. Olshen, and C. J. Stone (1984), Classification and Regression Trees, Wadsworth, Belmont, Calif.
Brumhard, B. (1991), Lysimeterversuche zum Langzeitverhalten der Herbizide Metamitron (GOLTIX ${ }^{\mathrm{B}}$ ) und Methabenzthiazuron (TRIBUNIL ${ }^{\mathrm{B}}$ ) in einer Parabraunerde mit besonderer Berucksisctigung der Transportund Verlagerungsprozesse unter Ein beziehung von Detailuntersuchungen, Band 2465, report, Forschungszent. Juelich, Juelich, Germany.

de Jonge, L. W., C. Kjaergaard, and P. Moldrup (2004), Colloids and colloid-facilitated transport of contaminants in soils: An introduction, Vadose Zone J., 3, 321-325.

Dressel, J. (2003), Transport von Ethidimuron, Methabenzthiazuron und Wassertracern in einer Parabraunerde, Ph.D. thesis, Inst. fuer Chem. und Dyn. der Geosphaere IV, Juelich, Germany.

Edwards, W., M. Shipitalo, W. Dick, and L. Owen (1992), Rainfall intensity affects transport of water and chemicals through macropores in no-till soils, Soil Sci. Soc. Am. J., 57, 1560-1567.

Flury, M. (1996), Experimental evidence of transport of pesticides through field soils-A review, J. Environ. Qual., 25(1), 25-45.

Giambelluca, T. W., K. Loague, R. E. Green, and M. A. Nullet (1996), Uncertainty in recharge estimation: Impact on groundwater vulnerability assessments for the Pearl Harbor basin, O'ahu, Hawai'i, USA, J. Contam. Hydrol., 23(1-2), 85-112, doi:10.1016/0169-7722(95)00084-4.

Hayes, T., K. Haston, M. Tsui, A. Hoang, C. Haeffele, and A. Vonk (2003), Atrazine induced hermaphroditism at $0.1 \mathrm{ppb}$ in American leopard frogs (Rana pipiens): Laboratory and field evidence, Environ. Health Perspect., 111(4), 568-575.

Heppell, C. M., F. Worrall, T. P. Burt, and R. J. Williams (2002), A classification of drainage and macropore flow in an agricultural catchment, Hydrol. Processes, 16(1), 27-46, doi:10.1002/hyp.282.

Insightful Corporation (2005), S-PLUS Version 7.0 for Windows: Manual, Seattle, Wash.

Kasteel, R., T. Pütz, and H. Vereecken (2006), An experimental and numerical study on flow and transport in a field soil using zero-tension lysimeters and suction plates, Eur. J. Soil Sci., 58, 632-645, doi:10.1111/ j.1365-2389.2006.00850.x.

Kladivko, E. J., L. C. Brown, and J. L. Baker (2001), Pesticide transport to subsurface tile drains in humid regions of North America, Crit. Rev. Environ. Sci. Tech., 31(1), 1-62, doi:10.1080/20016491089163.

Leonard, R. (1990), Movement of pesticides into surface waters, in Pesticides in the Soil Environment, edited by H. Cheng, pp. 303-349, Soil Sci. Soc. Am., Madison, Wis.

Malone, R. W., J. Weatherington-Rice, M. J. Shipitalo, N. R. Fausey, L. Ma, L. R. Ahuja, R. D. Wauchope, and Q. Ma (2004), Herbicide leaching as affected by macropore flow and within-storm rainfall intensity variation: A RZWQM simulation, Pest Manage. Sci., 60, 277-285.

McCarty, L. S., and C. J. Borgert (2006), Review of the toxicity of chemical mixtures: Theory, policy, and regulatory practice, Regul. Toxicol. Pharmacol., 45, 119-143, doi:10.1016/j.yrtph.2006.03.004.

McGrath, G. S., C. Hinz, and M. Sivapalan (2007), Temporal dynamics of hydrological threshold events, Hydrol. Earth Syst. Sci., 11, 923-938.

McGrath, G. S., C. Hinz, and M. Sivapalan (2008a), Modeling the impact of within-storm variability of rainfall on the loading of solutes to preferential flow pathways, Eur. J. Soil Sci., 59, 24-33, doi:10.1111/j.13652389.2007.00987.x.

McGrath, G. S., C. Hinz, and M. Sivapalan (2008b), Modeling the effect of rainfall intermittency on the variability of solute persistence at the soil surface, Water Resour. Res., 44, W09432, doi:10.1029/2007WR006652.

Muller, K., R. E. Smith, T. K. James, P. T. Holland, and A. Rahman (2003), Spatial variability of atrazine dissipation in an allophanic soil, Pest Manage. Sci., 59(8), 893-903, doi:10.1002/ps.693.

Nolan, B. T., I. G. Dubus, N. Surdyk, H. J. Fowler, A. Burton, J. M. Hollis, S. Reichenberger, and N. J. Jarvis (2008), Identification of key climatic factors regulating the transport of pesticides in leaching and to tile drains, Pest Manage. Sci., 64, 933-944, doi:10.1002/ps.1587.

Pütz, T. (1993), Lysimeterversuche zum Verlagerungsverhalten von Methabenzthiazuron und gelöstem organischen Kohlenstoff in einer Parabraunerde, Aufbau von zwei Klimamestationen und Untersuchungen zur Validierung des Lysimetersystems, Band 2812, report, Forschungszent. Juelich, Juelich, Germany.

Pütz, T., W. Mittelstaedt, and F. Führ (1998), Seasonal changes of [phenylu-'4c]-methabenzthiazuron loads in soil solution under practical farming conditions, Chemosphere, 31(8), 1531-1545.

Pütz, T., H. Vereecken, and B. Brumhard (1999), Water movement and pesticide transport on various scales, in Modeling of Transport Processes in Soils at Various Scales in Time and Space, pp. 536-545, Wageningen Press, Wageningen, Netherlands.

Qian, S., and C. Anderson (1999), Exploring factors controlling the variability of pesticide concentrations in the Willamette River basin using tree- 
based models, Environ. Sci. Technol., 33, 3332-3340, doi:10.1021/ es9812148.

Robinson, J., and M. Sivapalan (1997), Temporal scales and hydrological regimes: Implications for flood frequency scaling, Water Resour. Res., 33(12), 2981-2999, doi:10.1029/97WR01964.

Rouchaud, J., P. Roucourt, M. V. Himme, F. Benoit, N. Ceustermans, J. Gillet, W. Plumier, and G. Vulsteke (1998), Metabolism of methabenzthiazuron in the soil of pea crops, J. Agric. Food Chem., 36, 642-645, doi:10.1021/jf00081a059.

Simunek, J., K. Huang, and M. T. van Genuchten (1998), The HYDRUS code for simulating the one-dimensional movement of water, heat, and multiple solutes in variably saturated media, version 6.0, Res Rep. 144, 164 pp., U.S. Salinity Lab., Agric. Res. Serv., U.S. Dep. of Agric., Riverside, Calif.

Steenhuis, T. S., J. Boll, G. Shalit, J. S. Selker, and I. A. Merwin (1994), A simple equation for predicting preferential flow solute concentrations, J. Environ. Qual., 23(5), 1058-1064.

Struthers, I., C. Hinz, M. Sivapalan, G. Deutschmann, F. Beese, and R. Meissner (2003), Modeling the water balance of a free-draining lysimeter using the downward approach, Hydrol. Processes, 17(11), $2151-$ 2169, doi:10.1002/hyp.1326.

Struthers, I., C. Hinz, and M. Sivapalan (2007), Conceptual examination of climate-soil controls upon rainfall partitioning in an open-fractured soil: I. Single storm response, Adv. Water Res., 30(3), 505-517, doi:10.1016/ j.advwatres.2006.04.006.

Venables, W., and B. Ripley (1994), Modern Applied Statistics With S-Plus, 2nd ed., Springer, New York.
Vereecken, H. (2005), Mobility and leaching of glyphosate: A review, Pest Manage. Sci., 61, 1139-1151, doi:10.1002/ps.1122.

Wüstemeyer, A. (2000), Abbau und Transport von Ethidimuron und Methabenzthiazuron in einer Parabraunerde, Beitrag zur Validierung des Lysimeterkonzepts, Ph.D. dissertation, Rheinische Friedrich-Wilhelms-Univ., Bonn, Germany.

Zetler, F. I. (1998), Ungestö Säulenversuche zum von Sorptionsverhalten von [14C]Ethidimuron und Bromid in einer Parabraunerde aus Schwemmlö in Abhängigkeit der Beregnungsintensität und Batchversuch zur Berechnung von Adsorptionsund Desorptionsisothermen und Verteilungskoeffizienten von Ethidimuron, M.S. thesis, Dep. of Chem. Eng., Univ. of Appl. Sci. Aachen, Aachen, Germany.

J. Dressel, BASF SE, Carl-Bosch-Str. 64, D-67117 Limburgerhof, Germany. (joachim.dressel@basf.com)

C. Hinz and G. S. McGrath, School of Earth and Environment, University of Western Australia, 35 Stirling Hwy., Crawley, WA 6009, Australia. (chinz@cyllene.uwa.edu.au; gavan.mcgrath@uwa.edu.au)

T. Pütz and H. Vereecken, Agrosphere, ICG-4, Forschungszentrum Jülich GmbH, Leo-Brandt-Str., D-52425 Jülich, Germany. (t.puetz@fz-juelich.de; h.vereecken@fz-juelich.de)

M. Sivapalan, Department of Geography, University of Illinois at Urbana-Champaign, 220 Davenport Hall, 607 S. Mathews Ave., Urbana, IL 61801, USA. (sivapala@uiuc.edu) 